\title{
Histone acetylation and an epigenetic code
}

\author{
Bryan M. Turner
}

\begin{abstract}
Summary
The enzyme-catalyzed acetylation of the N-terminal tail domains of core histones provides a rich potential source of epigenetic information. This may be used both to mediate transient changes in transcription, through modification of promoter-proximal nucleosomes, and for the longer-term maintenance and modulation of patterns of gene expression. The latter may be achieved by setting specific patterns of histone acetylation, perhaps involving acetylation of particular lysine residues, across relatively large chromatin domains. The histone acetylating and deacetylating enzymes (HATs and HDACs, respectively) can be targeted to specific regions of the genome and show varying degrees of substrate specificity, properties that are consistent with a role in maintaining a dynamic, acetylation-based epigenetic code. The code may be read (ie. exert a functional effect) either through non-histone proteins that bind in an acetylation-dependent manner, or through direct effects on chromatin structure. Recent evidence raises the interesting possibility that an acetylationbased code may operate through both mitosis and meiosis, providing a possible mechanism for germ-line transmission of epigenetic changes. BioEssays 22:836-845, 2000. (C) 2000 John Wiley \& Sons, Inc.
\end{abstract}

\section{Introduction}

A quarter of a century has passed since the nucleosome was first recognised as the fundamental unit of chromatin structure in eukaryotic cells. In this time, its perceived role has expanded from a DNA-packaging element to a crucial determinant of virtually all aspects of genomic function. ${ }^{(1)}$ The isolated nucleosome core particle comprises a histone

Chromatin and Gene Expression Group, Anatomy Department University of Birmingham Medical School, Birmingham B15 2TT, UK. E-mail: b.m.turner@bham.ac.uk

Abbreviations: ChIP, Chromatin ImmunPrecipitation; Fab-7, Drosophila DNA sequence that can activate and suppress transcription in cis; H4Ac5 $(8,12,16)$, Histone $\mathrm{H} 4$ acetylated at lysine residue 5 $(8,12,16)$; HAT, Histone AcetylTransferase; HDAC, Histone Deacetylase; MBD2, Methyl Binding Domain protein 2; MeCP2, Methyl CpGbinding Protein 2; MOF, Drosophila histone acetyltransferase named after its mutant phenotype and chromosome location (Males-absent On the First); Rpd3p, An important yeast transcriptional regulator and histone deacetylase; SAGA, Yeast acetyltransferase complex named after some of its constituent proteins; white, Drosophila gene whose activity is necessary for the red eye colour of wild-type flies; its mutation gives a white-eyed phenotype. octamer, two copies each of $\mathrm{H} 2 \mathrm{~A}, \mathrm{H} 2 \mathrm{~B}, \mathrm{H} 3$ and $\mathrm{H} 4$, around which is wrapped 146 base pairs of DNA. This structure is the same in virtually all eukaryotes. However, in vivo this extremely conserved structure is subject to numerous enzyme-catalyzed manipulations and modifications that give it an almost infinite capacity for variability. A major contributor to this heterogeneity is the enzyme-catalyzed, post-translational modification of the $\mathrm{N}$-terminal tails of the eight core histones. The tails are exposed on the nucleosome surface and can be modified by acetylation, phosphorylation, methylation, ubiquitination and ADP-ribosylation of specific amino acids. ${ }^{(2)}$ Of these modifications, acetylation of the $\varepsilon$ amino group of defined lysine residues is the most frequently occurring and extensively studied.

Any discussion of the possible functions of histone modification must take account of the fact that the nucleosome is involved, one way or another, in virtually every activity of nuclear DNA, including transcription, replication and repair. It is difficult, possibly unwise, to consider these activities in isolation. With this in mind, this review will focus on an aspect of the subject that has received, till recently, relatively little attention. It will explore the possibility that histone modifications provide a mechanism for encoding and transmitting information about genomic function from one cell generation to the next; in other words, an epigenetic code. In what follows, histone acetylation will provide most of the experimental examples, but the possibilities discussed may equally well be applied to other modifications whose analysis is still at a relatively early stage. In fact, it is becoming increasingly clear that important functional effects can depend on precise combinations of modifications.

\section{Finding coded messages}

The idea that chromatin in general and patterns of histone acetylation in particular may constitute a code that transmits epigenetic information has been suggested before ${ }^{(3-8)}$, but recent experiments have provided valuable insights into the nature of the putative code and how it might operate. There are several examples, some long standing, of specific modifications that are associated with defined functional effects. These are listed in Table 1. The potential importance of combinations of modified residues has been emphasized more recently by studies of phosphorylation of $\mathrm{H} 3$ serine 10 . This residue is phosphorylated at high frequency as cells 
Table 1. Residue-specific, histone modifications associated with defined functional effects

\begin{tabular}{|c|c|c|c|}
\hline $\begin{array}{l}\text { Modification } \\
\text { (histone:residues) }\end{array}$ & $\begin{array}{l}\text { Modification of } \\
\text { Adjacent Lysines }\end{array}$ & Organism & Functional Association \\
\hline $\mathrm{H} 4: \mathrm{K} 5 \mathrm{Ac}^{(1)}$ & Probably acetylated ${ }^{(2)}$ & S. cerevisiae & $\begin{array}{l}\text { Causes derepression of UME6-regulated genes in rpd3 } \\
\text { deletion mutants }\end{array}$ \\
\hline $\mathrm{H} 4: \mathrm{K} 12 \mathrm{Ac}$ & Underacetylated & Drosophila, S. cerevisiae & $\begin{array}{l}\text { Heterochromatin formation. Silencing of } H M \text { genes in yeast, } \\
\text { needs unmodified } \mathrm{K} 16\end{array}$ \\
\hline $\mathrm{H} 4: \mathrm{K} 16 \mathrm{Ac}$ & Acetylated $^{(2)}$ & Drosophila & 2 -fold increase in transcription on male $X$ \\
\hline H4 (non-acetylated) & $\begin{array}{l}\text { All non-acetylated } \\
\text { (also } \mathrm{H} 2 \mathrm{~A}, \mathrm{H} 2 \mathrm{~B}, \mathrm{H} 3 \text { ) }\end{array}$ & Mammals & Constitutive (centric) and facultative heterochromatin \\
\hline $\mathrm{H} 4: \mathrm{K} 5 \mathrm{Ac}, \mathrm{K} 12 \mathrm{Ac}$ & Non-acetylated & All tested & $\begin{array}{l}\text { New } \mathrm{H} 4 \text { for chromatin assembly; role in chromatin } \\
\text { accessibility? non-essential in yeast }\end{array}$ \\
\hline $\mathrm{H} 3: \mathrm{S}_{10 \mathrm{P}^{(1)}}$ & Acetylated & Mammals & Up-regulation of Immediate Early genes by growth factors \\
\hline H3:S10P & Underacetylated(?) & All tested & $\begin{array}{l}\text { Chromatin condensation through mitosis and meiosis; } \\
\text { essential }\end{array}$ \\
\hline $\mathrm{H} 3: \mathrm{K} 9 \mathrm{Ac}, \mathrm{K} 14 \mathrm{Ac}$ & Non-acetylated & Tetrahymena & Newly systhesized $\mathrm{H} 3$ for chromatin assembly \\
\hline H3:K14Ac,K23Ac & Non-acetylated & Drosophila & Newly synthesized $\mathrm{H} 3$ for chromatin assembly \\
\hline
\end{tabular}

(1) Ac, acetylated; P, phosphorylated. (2) Adjacent lysines are acetylated at essentially the same frequency as in bulk chromatin. (3) References to the original papers on which this table is based, or to relevant reviews, are in the text.

enter and pass through mitosis and its substitution by site directed mutagenesis results in abnormal chromatin condensation. ${ }^{(9,10)} \mathrm{H} 3 \mathrm{~S} 10$ is also phosphorylated, in a small subfraction of $\mathrm{H} 3$, during the upregulation of immediate-early genes in response to growth factors (reviewed in Ref. 11). The puzzle as to how the same modification can be associated with two such different, at first sight diametrically opposed, functional effects may be resolved by the observation that H3 phosphorylated during growth factor stimulation is also likely to be hyperacetylated. ${ }^{(12)}$ Acetylation of lysines adjacent to S10 may help generate a distinct transcriptional signal. Two recent papers ${ }^{(13,14)}$ have shown that this is indeed the case. Several histone acetyltransferases (HATs) were shown to have increased activity in vitro against $\mathrm{H} 3$ peptides phosphorylated at $\mathrm{S} 10$. In the yeast HAT GCN5, substitution of a specific residue (R164), likely to lie adjacent to $\mathrm{H} 3 \mathrm{~S} 10$ in the enzyme-substrate complex, abolished this effect. Significantly, this same mutation resulted in reduced activity in vivo at a subset of Gcn5dependent promoters. ${ }^{(14)}$ Transcription of the same subset of genes was diminished in mutants carrying a substitution of H3S10. The results presented in these publications make the important general point that one modification (in this case phosphorylation) can influence the probability that a second modification (in this case acetylation) will occur, and may also moderate its functional effects.

A different version of the same general effect may be provided by work on yeast mutants in which silencing of genes under the control of the transcriptional regulator UME6 is disrupted. UME6 operates by recruiting, to selected genes, a high molecular weight complex containing, amongst other things, the histone deacetylase RPD3 and the silencing protein SIN3. Chromatin immunoprecipitation (ChIP) and multiplex PCR have been used to show that, in rpd3 mutants, nucleosomes within about $1 \mathrm{~kb}$ of the promoters of UME6regulated genes show a selective, several-fold increase in acetylation of $\mathrm{H} 4 \mathrm{~K} 5 .^{(15)}$ In $\sin 3$ mutants, increases in acetylation at $\mathrm{H} 4 \mathrm{~K} 5$ and $\mathrm{H} 4 \mathrm{~K} 12$ were noted in the same region. The results show that silencing complexes can selectively deacetylate specific histone lysines, and that the lysines selected may depend on the composition of the complex. What is the molecular context in which the $\mathrm{H} 4$ acetylation/deacetylation switch operates in this system? Are H4 lysines generally acetylated along UME6regulated genes, in which case the switch will be primarily between the tri-acetylated to tetra-acetylated isoforms, or are they underacetylated, in which case the functional change must be an effect of lysine-specific acetylation alone?

The most long-standing and highly conserved example of lysine-specific histone acetylation is the di-acetylation of newly synthesized $\mathrm{H} 4$ at lysines 5 and 12 , in which form it is deposited on newly replicated DNA during chromatin assembly. ${ }^{(16,17)}$ In view of the extreme evolutionary conservation of this very specific modification, it is surprising that cell growth and chromatin assembly continue in yeast mutants in which these two residues have been substituted. Such mutants do show a lengthening of S-phase ${ }^{(18)}$ but only by substitution of $\mathrm{H} 4$ lysines 5,8 and 12 , together with deletion of the H3 tail, could a severe chromatin assembly defect be induced. ${ }^{(19)}$ It seems that $\mathrm{H} 4$ di-acetylation at lysines 5 and 12 facilitates chromatin assembly in a way that is evolutionarily advantageous, but is not an essential component of the chromatin assembly mechanism. It may be that the functional importance of this modification lies outside the chromatin assembly mechanism itself. One 
interesting possibility is that $\mathrm{H} 4$ di-acetylation prevents newly assembled chromatin from adopting a "closed" conformation until such time as transcription factors and chromatinmodifying enzymes have been able to gain access and make any adjustments necessary to maintain or modify its conformation. Both biochemical ${ }^{(20)}$ and microscopical ${ }^{(21)}$ analyses indicate that $\mathrm{H} 4$ on newly assembled chromatin remains di-acetylated for several minutes before its removal by deacetylases, allowing time for such adjustments to take place.

\section{Encryption mechanisms}

Overall levels of histone acetylation are determined by the combined activities of two enzyme families, the Histone Acetyltransferases (HATs) and deacetylases (HDACs). If, as seems likely, these enzymes are responsible for setting patterns of acetylation across the genome, then they must be both targetable to defined genomic regions and have a range of specificities sufficient, at least, to account for the patterns of acetylation listed in Table 1. Both requirements are close to being met.

Both HATs (22 and references therein) and HDACs (reviewed in Ref. 23) can be targeted to their sites of action on chromatin by association with a variety of DNA-binding, transactivator proteins. In some cases, the targeting involves other chromatin modifications or modifying activities. For example, in S. cerevisiae the SAGA HAT complex seems to be targeted to the promoter region of the $\mathrm{HO}$ gene by a mechanism involving various DNA-binding proteins and requiring the chromatin remodeling activity of the Swi/Snf complex. ${ }^{(24)}$ (This is discussed further below.) In mammals, histone deacetylases are targeted to methylated regions of the genome through association with the methyl-DNAbinding proteins MeCP2 and MBD2 ${ }^{(23)}$ and, possibly, the DNA methyltransferase itself. ${ }^{(25)}$ On a larger scale, targeting to nuclear domains rich in heterochromatin can be achieved through association with Ikaros and related proteins. ${ }^{(26,27)}$

Several members of the HAT family have been shown to acetylate preferentially specific histones and/or specific lysines. ${ }^{(28-31)}$ Not surprisingly, the preferences can vary depending on whether the enzyme is presented with peptides, free histones or chromatin. In addition, most HATs are found in vivo as multiprotein assemblies and substrate specificities can be altered by the proteins with which the catalytic subunit is associated. ${ }^{(32)}$ A nuclear HAT has recently been shown to exhibit a specificity that corresponds exactly to a known, functionally significant pattern of histone acetylation and to be targeted to its site of action. The acetyltransferase MOF is an essential component of the dosage compensation complex that coats the $\mathrm{X}$ chromosome in male Drosophila. ${ }^{(33,34)}$ Male flies lacking MOF activity fail to upregulate transcription of genes on their single $\mathrm{X}$ chromosome and die early in development. MOF, as a recombinant protein ${ }^{(34)}$ or as a component of multisubunit, dosage compensation complexes isolated from Drosophila cultured cells, ${ }^{\left({ }^{33)}\right.}$ has now been shown to acetylate $\mathrm{H} 4$ in chromatin specifically at lysine 16 . This is exactly the modification that is found, almost uniquely, along the Drosophila male $\mathrm{X}$ chromosome at multiple sites corresponding to those also occupied by the dosage compensation complex. ${ }^{(35,36)}$

Studies on the catalytic specificities of histone deacetylases have been less extensive, but they too can show specificity for particular histone lysines depending on the substrate $^{(37)}$ and the composition of the enzyme. ${ }^{(15,38)} \mathrm{A}$ novel, NAD-dependent histone deacetylase from yeast, Sir2 $p$, shows a remarkably strong preference for deacetylating $\mathrm{H} 4$ lysine16, at least with a peptide substrate. ${ }^{(39)}$ Unfortunately, the Drosophila homologue, while sharing the NAD dependence of the yeast enzyme, does not show the same interesting specificity for $\mathrm{H} 4$ lysine 16 (Andrew Barlow and B. M. T., unpublished).

\section{Reading the code; structure matters}

The histone tails have traditionally been described as random coil, ie. essentially without a defined, stable structure. This lability is well suited to a protein recognition function and for models that explain the functional effects of tail modifications through their influence on binding of non histone proteins. ${ }^{(3,35)}$ The strength and specificity of binding will derive from the imposition of a structure on the selected region of the tail, an "induced fit". However, recent evidence suggests that the histone tails in chromatin may have a greater degree of structure than was previously suspected. Comparison of the circular dichroism spectra of intact core particles with those lacking the trypsin-sensitive tail regions of $\mathrm{H} 3$ and $\mathrm{H} 4$, indicates that these regions are $50 \% \alpha$ helical. ${ }^{(40)}$ The sequence elements involved could not be defined, but predictive algorithms based on known sequence:structure correlations indicate some likely regions. ${ }^{(41)}$ Data for histones $\mathrm{H} 3$ and $\mathrm{H} 4$, the ones for which most information is available, is summarised in Fig. 1, together with genetically determined, functional attributes of different regions of the two tails. ${ }^{(42,43)}$ These results and speculations must still be reconciled with the fact that, in core particle crystals, the most $\mathrm{N}$-terminal tail regions (eg. residues 1-15 of $\mathrm{H} 4$ ) are not detectable by X-ray crystallography, even when the core particles are assembled from recombinant (i.e. unmodified) histones. ${ }^{(44,45)}$ This shows an absence of consistent structure. The procedures used to prepare crystals will give different tail conformations to those seen in solution at low ionic strength, and neither set of experimental conditions even approximates to the situation in vivo.

If we accept that, at least in some circumstances, the tails are part of a highly structured and interlinked complex of

\section{BioEssays 22.9}




\section{HISTONE TAILS}

H4

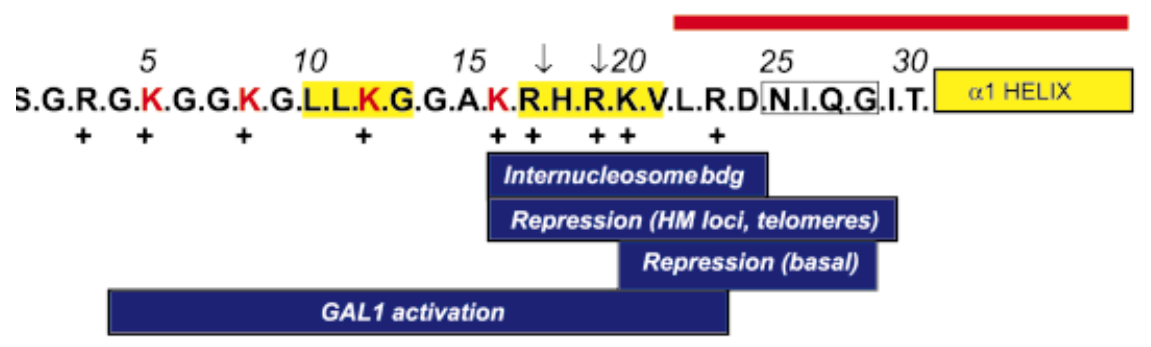

H3

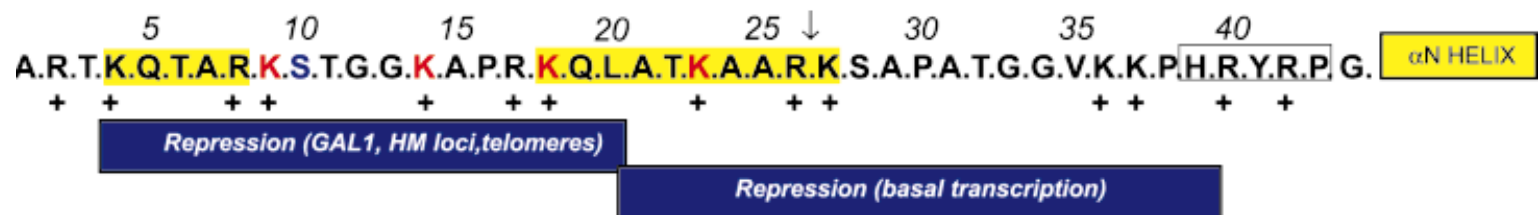

Figure 1. The sequences of the amino terminal tail regions of histones $\mathrm{H} 3$ and $\mathrm{H} 4$ are shown in single letter code. Lysines that can be acetylated in animal cells are shown in red and the phosphorylatable $\mathrm{H} 3$ serine, $\mathrm{S} 10$, in blue. Positively charged residues are marked $(+)$ below the sequence. The regions for which structures have been resolved by X-ray analysis of core particle crystals are shown by red lines above the sequence. Arrows indicate sites at which trypsin can cleave the tails to produce tailless core particles. Boxed residues are the short " $3-10$ " helix in $\mathrm{H} 4$ and the five $\mathrm{H} 3$ residues that pass through a channel formed by the minor grooves of adjoining DNA helices. ${ }^{(44)}$ Regions highlighted in yellow are predicted to form $\alpha$-helices by at least two of four structural prediction procedures. ${ }^{(41)}$ The blue boxes beneath the sequences show regions associated with defined functions. The H4 "internucleosomal binding" domain was identified in core particle crystals. The rest have been identified by mutational analysis in yeast (Ref. 42 and references therein).

protein-nucleic acid interactions, it is much more likely that modification (or substitution) of single residues will lead to defined, and specific, changes in chromatin conformation. A high degree of secondary structure in the histone tail domains also means that a modification or substitution in one region is potentially able to cause a structural change in a distant region. Such knock-on effects could explain results in which various $\mathrm{H} 4$ mutations, which causes mating defects in yeast by derepressing the $H M L$ gene, are all suppressed by the same mutation in the tail-binding, silencing protein Sir3p. ${ }^{(42)}$ In molecular terms, the explanation requires that any mutation, or modification, that disrupts one region of the H4 tail (in this example amino acids 16-19) can alter the protein-binding properties of an adjacent, possibly overlapping, region in a specific and consistent way.

\section{Long-term and short-term changes}

Many biological situations require a transient upregulation or downregulation of gene activity. Rather than maintaining a pattern of activity, the task is to ensure that it is only shortlived. Recent experiments, using chromatin immunoprecipitation (ChIP) techniques, have shown that increased acetylation of histones $\mathrm{H} 3$ and $\mathrm{H} 4$ on promoter proximal nucleosomes is associated with initiation of transcription on inducible genes in various organisms. ${ }^{(46-49)}$ The specific lysine residues involved have not yet been defined, though in some systems differences have been noted in the degree to which acetylation of $\mathrm{H} 3$ and $\mathrm{H} 4$ changes, suggesting that acetylation of these two histones is regulated independently. The important point about these observations, in the context of the present discussion, is that the acetylation changes described are (a) local, sometimes confined to only two or three, promoter proximal nucleosomes; (b) closely correlated with transcription initiation; and (c) transient, returning to baseline levels when transcription falls. These properties contrast with the well established, developmentally regulated changes in acetylation across the globin genes, ${ }^{(50)}$ where regions of increased histone acetylation extending over tens of kb seem to provide the potential for transcription, possibly several cell cycles ahead of the onset of transcription itself. The $\mathrm{HO}$ gene in S.cerevisiae provides an example of a gene whose regulation may involve both long-term and transient changes in acetylation. The gene encodes an endonuclease required for mating type switching and is under the control of a complex network of regulator proteins. It is expressed for only a few minutes late in the $\mathrm{G}_{1}$ phase of the second cell cycle after germination of a haploid spore, and only in "mother" cells, not the smaller, bud-derived "daughters" 
(Ref. 24 and references therein). In an elegant series of ChIP experiments, Cosma et al. ${ }^{(24)}$ have shown that initiation of transcription involves the sequential binding, through late anaphase and telophase, of Swi5p, Swi4p, Swi6p, the Swi/ Snf complex and the SAGA (Gcn5p-containing) HAT complex. Binding of Swi5p is transient, but the other components remain in place until $\mathrm{HO}$ transcription begins late in $\mathrm{G}_{1}$. In complementary experiments, Krebs et al. ${ }^{(49)}$ have used ChIP with antibodies to $\mathrm{H} 3$ acetylated at lysines 9 and 14 and "hyperacetylated" $\mathrm{H} 4$, to show a transient increase in acetylation in a $1 \mathrm{~kb}$ region upstream of the transcription start site, just prior to the onset of $\mathrm{HO}$ transcription. They also found that the baseline level of acetylation across the $\mathrm{HO}$ domain was significantly lower than that of the rest of the yeast genome. As usual in yeast, mutants provided valuable information about possible mechanisms. Mutants lacking Rpd3p deacetylase activity, had elevated acetylation levels across the genome, with no relative underacetylation of the $\mathrm{HO}$ domain. In such mutants, transient expression of $\mathrm{HO}$ in late $\mathrm{G}_{1}$ occurred essentially as normal, but was not accompanied by any local changes in histone acetylation. In contrast, these mutants failed to silence $\mathrm{HO}$ in "daughter" cells and showed inappropriate control of $\mathrm{HO}$ expression in response to mating pheromones (discussed in Ref. 49). Thus, whereas functional Rpd3p and histone deacetylation are not necessary for the appropriate regulation of $\mathrm{HO}$ through the cell cycle, they are necessary for its correct expression in different cell types or in response to external signals. Perhaps the low basal level of histone acetylation across the $\mathrm{HO}$ domain, apparently maintained by Rpd3p, provides a stable genomic mark that is needed for correct control of $\mathrm{HO}$ expression in some situations but not others. Conversely, increased histone acetylation, dependent on GCN5, may provide a (transient) chromatin environment that is permissive for transcription. This work provides a fascinating example of the interaction of acetylating and deacetylating activities and poses new questions regarding their targeting, specificities and how their catalytic activities are regulated.

\section{Transmitting the code}

A code is essentially a means of transmitting information and, if histone modifications are to earn their keep as a true epigenetic code, then they must, at the very least, be able to transmit information from one cell generation to the next. Evidence that $\mathrm{H} 4$ acetylation can function in exactly this way comes from experiments in the yeast $S$. pombe. Increased expression of a gene inserted adjacent to centric heterochromatin could be induced by treatment with the HDAC inhibitor Trichostatin A (TSA) and then maintained, through many cell generations, in the absence of the inhibitor. ${ }^{(51)}$ The question of mechanism remains unanswered: in particular, how can patterns of acetylation be duplicated on the two sister strands following DNA replication and a chromatin assembly mechanism that involves deposition of diacetylated $\mathrm{H} 4$ followed by a major round of histone deacetylation? We do not yet know whether this deacetylation involves only lysines 5 and 12 on newly deposited $\mathrm{H} 4$, or all acetylated lysines. In the latter case, patterns of acetylation must be put in place from scratch after each round of DNA replication and chromatin assembly.

The simplest maintenance mechanism would be for the HATs and HDACs responsible for patterns of acetylation to remain in the vicinity during replication and reassociate with newly assembled chromatin following passage of the replication fork. This would be an appropriate mechanism for HATs such as MOF that form part of a complex that remains associated with its target DNA throughout the cell cycle. $^{(36,52,53)}$ A more general maintenance mechanism could operate through recruitment of HDACs to methylated DNA via their association with methyl-DNA-binding proteins such as MeCP2 and MBD2 and with the DNA methyl transferase itself. ${ }^{23,25)}$ This mechanism could certainly account for the association between DNA methylation and histone underacetylation found in various types of heterochromatin.

A mechanism that offers the possibility of maintaining acetylation patterns even more specifically, is the recruitment of HATs to chromosome regions showing patterns of histone acetylation that correspond to their own catalytic specificity. ${ }^{(6,7)}$ This mechanism becomes less hypothetical in light of the demonstration that the bromodomain of the HAT P/ CAF binds preferentially to $\mathrm{H} 4$ and $\mathrm{H} 3$ peptides containing an acetylated lysine. ${ }^{(54)}$ The bromodomain is a protein motif shared by many HATs (and other proteins) and is believed to be important for protein-protein interactions. It will be interesting to see if other HAT bromodomains show similar binding properties and, if they do, if the binding can be regulated to give the level of specificity that the proposed targeting mechanism requires.

\section{A higher-order code}

In most cells, histone acetylation is a common modification, even in mature chromatin, and only a minute proportion of the cell's acetylated chromatin can be involved in transcription initiation at the promoter. The rest is likely to be concerned with setting patterns of chromatin structure over much wider stretches of the genome. Recurring patterns of histone acetylation at the highest levels of chromatin structure, as predicted by such models, are seen in the form of bands of acetylated and non-acetylated chromatin in the interphase polytene chromosomes of chironimid insects. ${ }^{(35)}$ The very existence of such sharply delineated regions of $\mathrm{H} 4$ acetylation along the one thousand or so parallel chromatin fibres that constitute a polytene chromosome, argues for mechanisms that maintain patterns of acetylation from one round of DNA replication to the next.

\section{BioEssays 22.9}


Perhaps the most extreme examples of higher-order coding are found in the dosage compensation mechanisms in Drosophila and mammals. In both cases, an entire $X$ chromosome is marked across almost its whole length by a specific pattern of $\mathrm{H} 4$ acetylation. In both cases, the distinctive pattern of acetylation is present in both interphase and metaphase chromosomes. ${ }^{(35,52,55,56)}$ In neither case is it clear whether the acetylation is part of a transcriptional regulation mechanism (giving a two-fold increase in transcription in Drosophila and silencing in mammals) or a signal by which a preset level of transcription is maintained from one cell cycle to the next. In differentiating mouse embryonic stem cells (ES cells), gene silencing and other properties associated with the inactive $\mathrm{X}(\mathrm{Xi})$ are detectable at least 2 days before global underacetylation, suggesting that the latter possibility may be the correct one. ${ }^{(57)}$ However, in attempting to come up with plausible mechanisms, it is important to remember that local changes in acetylation may be occurring at the same time as chromosome-wide changes detectable at the light microscope level. For example, deacetylation of a region upstream of the Xist gene precedes global deacetylation of $\mathrm{Xi}$ in ES cells. ${ }^{(56)}$ Experiments with human $\times$ hamster hybrid cells whose only human chromosome is $\mathrm{Xa}$ or $\mathrm{Xi}$, have provided evidence that deacetylation on $\mathrm{Xi}$, at least in interphase, is confined to the promoter regions of silenced genes. ${ }^{(58)}$ This is not the case in ES cells. ${ }^{(56)}$ Perhaps the difference reflects a relaxation of the requirement for maintenance of the silent state in hybrid cell lines.

\section{Germ-line transmission of epigenetic changes}

The hyperacetylated, transcriptionally active state of centromeric chromatin induced by treatment with TSA in the yeast $S$. pombe, is stably inherited through both mitosis and meiosis. ${ }^{(51)}$ Thus, progression through meiosis does not, in itself, necessarily reverse chromatin-based, epigenetic changes. An exploration of the ability of epigenetic changes to survive meiosis in higher eukaryotes has been made in Drosophila using the important regulatory element Fab-7. This DNA sequence derives from the Bithorax complex where it acts as a developmentally regulated enhancer and silencer in ways that depend on Polycomb Group (PcG) and trithorax Group (trxG) proteins. ${ }^{(59)}$ It carries these properties with it when moved out of its normal chromosome environment. A construct in which Fab-7 was attached to a GAL4dependent promoter (UAS), a lacZ reporter gene and a miniwhite gene (Fig. 2A), was stably inserted into the Drosophila genome to derive a series of stable lines. ${ }^{(60)}$ The mini-white gene was used as a transformation marker in a host with white eyes. The Fab-7 element acted as a silencer, reducing the expression of the white gene and resulting in flies with yellow eyes, rather than the expected dark red eyes. The lacZ gene is only expressed in the presence of the GAL4 transactivator, provided, for the purposes of these experiments, by a second construct crossed into these fly lines (Fig. 2A). The silencing of both reporter genes by Fab-7 was dependent on a competition between GAL4 and the PcG proteins. Increased levels of GAL4 could overcome PcG silencing.

The use of fly strains in which GAL4 was under the control of an inducible heat-shock promoter, gave revealing results. ${ }^{(61)}$ If embryos were subjected to a brief heat shock (30 minutes at $37^{\circ} \mathrm{C}$ ) and then allowed to develop at their normal growth temperature $\left(18^{\circ} \mathrm{C}\right)$, adult flies showed an increased frequency of red eye colour (Fig. 2B). The relief of inhibition induced by the transient increase in GAL4 had been maintained through many cell generations, long after GAL4 levels had fallen back to baseline. This effect was seen only if the heat shock was applied during embryonic development. Brief heat shock during the larval stages could still transiently induce the lac $Z$ gene, but did not lead to mitotically stable derepression of the mini-white gene (allowing it to be turned on at the appropriate stage later in development) and did not give red eye colouration in the adult (Fig. 2B).

Even though this system is an artificial one, the experiments make the important general point that an environmental change during early embryogenesis can alter the transcriptional potential of a gene in a way that is stably inherited through many cell generations, even in the absence of the original inductive signal. But the really surprising result was the observation that a significant proportion of the offspring of female flies in which the mini-white gene had been derepressed during early embryogenesis, showed red eye colouration and lacZ expression. ${ }^{(61)}$ This was seen even when crosses were constructed so that offspring did not have the GAL4 construct (ie. it could not be explained by the continued, low-level production of GAL4). Transmission through the male germ line was not observed.

What is the molecular mechanism responsible for the maintenance of patterns of expression through mitosis and meiosis? Recent experiments ${ }^{(62)}$ have used immunofluorescence microscopy to determine the acetylation status of the chromatin domain containing the Fab-7 element. A brief heat shock during the embryonic stage resulted in increased staining (with an antibody to tetra-acetylated H4) across the Fab-7 insertion site in third instar polytene chromosomes. Changes were not detected with an antibody to acetylated H3. In contrast, a similar heat-shock treatment of the larvae themselves caused only a weak and transient increase in $\mathrm{H} 4$ acetylation, becoming undetectable within 40 minutes. Due to staining of endogenous bands adjacent to the transgene insertion site in the fly line used for meiotic transmission experiments, increased acetylation of the transgene-containing domain was not demonstrable in the offspring, so meiotic transmission of the hyperacetylated state remains to be 


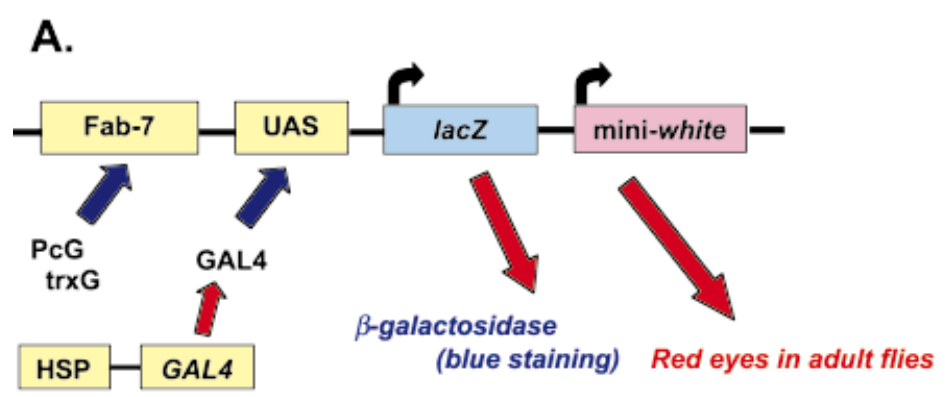

B.

\begin{tabular}{|c|c|c|c|c|c|c|}
\hline \multicolumn{6}{|c|}{$\beta$-gal expression before or after GAL4 induction ( ) } & \multirow{3}{*}{ ADULT EYES } \\
\hline Egg & Embryo & \multicolumn{2}{|c|}{ Larva } & Pupa & Adult & \\
\hline & & early & late & & & \\
\hline - & + & + & + & + & + & $\begin{array}{l}\text { Red/white } \\
\text { (variegated) }\end{array}$ \\
\hline - & - & $1+$ & - & - & - & white \\
\hline - & - & - & + & - & - & White \\
\hline
\end{tabular}

Figure 2. A diagram of the DNA construct used to monitor the effect of the transactivator GAL4 on UAS-induced expression of the lac $Z$ and mini-white genes. The Fab-7 element can silence expression or can maintain induced expression by mechanisms that are dependent, respectively, upon PcG proteins or trxG proteins. A: Fly lines in which the GAL4 transactivator was under the control of a heat shock promoter (HSP) were used to monitor the effects of a heat-shock-induced burst of GAL4 at different stages of development. If embryos were heat shocked at $37^{\circ} \mathrm{C}$, then returned to their normal growth temperature of $18^{\circ} \mathrm{C}$, the lac $Z$ marker gene was induced and remained active throughout development. The mini-white gene became sufficiently active to give at least partially red eyes in the majority of adult flies. The same heat shock throughout the larval stages (1st, 2nd or 3rd instar), gave only transient upregulation of lac $Z$ and no evidence of mini-white activation. These results are summarised from Ref. 61 (see text).

formally demonstrated. However, the results strongly suggest that changes in $\mathrm{H} 4$ acetylation form part of the mechanism by which this epigenetic change is transmitted mitotically and also eventually through the female germ line. A role for histones is certainly consistent with the absence of transmission through the male germ line, in which histones are almost completely displaced by protamines in the later stages of spermatogenesis. However, $\mathrm{H} 4$ acetylation is likely to be just one component in the germ-line transmission of chromatin states. Germ-line transmission of the active state of the Fab-7 construct was not seen in all fly lines tested, ${ }^{(62)}$ so may depend upon the site of insertion of the transgene. Also, activation of the mini-white gene after embryonic induction was stronger in males than females. Both the physiological and chromosomal context in which the activated transgene is placed seem able to influence its transmission. The exact nature of the acetylation changes induced by GAL4 induction also remains to be determined.

\section{Summary and future prospects}

A model summarizing, in general terms, the way in which histone acetylation might operate as an epigenetic code is presented in Fig. 3. It proposes that patterns of histone acetylation, for $\mathrm{H} 4$ at least, are set during post-replication chromatin assembly through targeting of specific histone acetyltransferases and deacetylases. The acetylation status determines chromatin structure and, thereby, its functional properties, either by directly initiating structural change or by regulating protein-histone interactions. Patterns of acetylation are maintained through the rest of the cell cycle, either through continuing enzyme activity, or by sheltering chromatin domains so as to render them refractory to further enzyme action. Environmental factors (eg. deacetylase inhibitors) when present at the crucial cell cycle or developmental stage, may induce changes in histone acetylation that are then perpetuated by the mechanisms discussed earlier. Any environmental agent that affects the activity, specificity

\section{BioEssays 22.9}


Figure 3. A simple model summarising how patterns of histone acetylation may be involved in the regulation of chromatin structure and function through the cell cycle. Patterns of acetylation are altered during post-replication chromatin assembly due to the deposition of newly synthesized, diacetylated $\mathrm{H} 4$ (in some species $\mathrm{H} 3$ is also diacetylated), followed by deacetylation. Patterns of acetylation are altered or maintained by targeting of HATs and HDACs of the appropriate specificity. The chromatin structure adopted by any given genomic region will depend, at least in part, on its pattern of histone acetylation. These patterns are maintained through the rest of the cell cycle either by the continuing activity of targeted enzymes or by sheltering chromatin domains against further enzyme activity. Sheltered domains will be impervious to the action of enzyme inhibitors, such as TSA, at least until the next round of DNA replication and chromatin assembly. At this stage, the genome will be particularly vulnerable to epigenetic changes induced by environmental factors.
A dynamic, epigenetic code based on patterns of histone acetylation

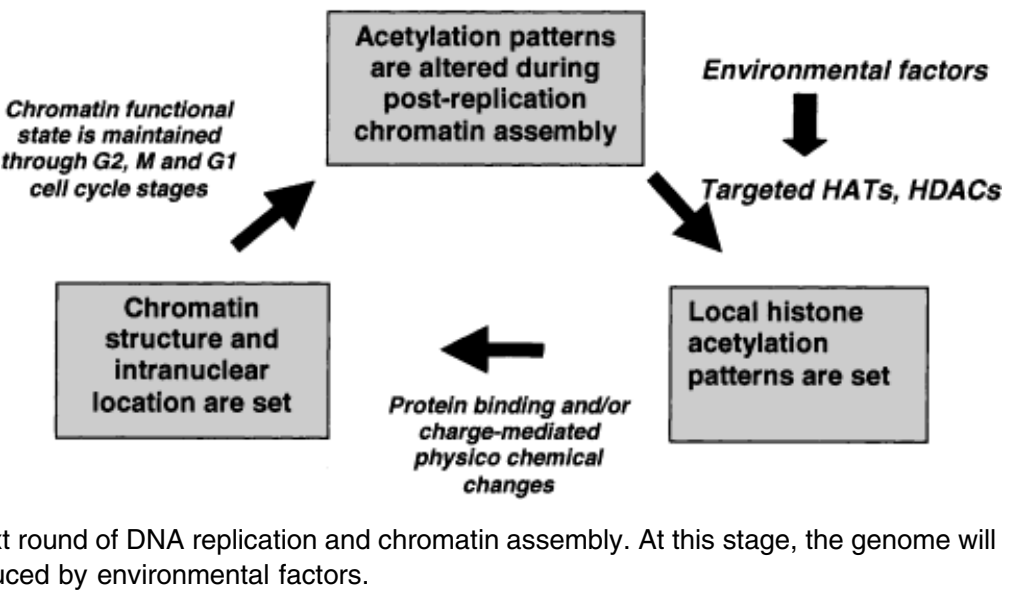

or targeting of the acetylating/deacetylating enzymes has the potential ability to cause a long-term, epigenetic change. Inhibitors of these enzymes need not be exotic, laboratory reagents. For example, the histone deacetylase inhibitor sodium butyrate is present at functionally significant levels in the human colon and is a possible inhibitor of the development of colon cancers (Ref. 63 and references therein). Conversely, environmentally induced, epigenetic changes are increasingly being associated with the pathogenesis of human cancers. ${ }^{(64)}$ The recent identification of a histone deacetylase, Sir2p, whose activity is NAD dependent, ${ }^{(39)}$ provides an exciting link between chromatin structure, gene regulation and metabolism. There is now a route by which dietary factors that influence NAD levels can not only impact directly on gene expression, but potentially initiate long-term, epigenetic changes through changes in histone acetylation.

Perhaps the major problem that must be solved before the model can be critically assessed and developed, is identification of the mechanistic links between histone acetylation and chromatin function. Neither for transient, promoter proximal changes nor for longer-term effects, has it been established exactly how acetylation of the histone tails exerts a functional effect. Nor do we yet fully appreciate the functional significance of combinations of histone modifications and how they may interact to give each chromatin domain a characteristic, and possibly unique, epigenetic signature. We also need to know how the HATs and HDACs (and other modifying enzymes) are targeted to their sites of action and what is the role of intranuclear location and replication timing. Finally, we need to identify the environmental and metabolic factors that influence the activity of chromatin-modifying enzymes. These factors may be more subtle and complex than conventional mutagens. What is not in doubt is that unravelling how chromatin-modifying enzymes induce long term, epigenetic changes and by what mechanisms they are regulated, will pay rich dividends in understanding the etiology of human diseases and devising novel therapies.

\section{Acknowledgments}

I am grateful to Geneviève Almouzni, Renato Paro and members of the Chromatin and Gene Expression Group for critical reading of the manuscript and constructive suggestions.

\section{References}

1. Kornberg RD, Lorch Y. Twenty-five years of the nucleosome, fundamental particle of the eukaryote chromosome. Cell 1999;98: 285-294.

2. Wolffe AP, Hayes JJ. Chromatin disruption and modification. Nucleic Acids Res 1999;27:711-720.

3. Turner BM. Decoding the nucleosome. Cell 1993;75:5-8.

4. Tordera V, Sendra R, Pérez-Ortin JE. The role of histones and their modifications in the informative content of chromatin. Experientia 1993; 49:780-788.

5. Jeppesen P. Histone acetylation: A possible mechanism for the inheritance of cell memory at mitosis. Bioessays 1997;19:67-74.

6. Turner BM. Histone acetylation as an epigenetic determinant of long-term transcriptional competence. Cell Mol Life Sci 1998;54: 21-31.

7. Grunstein M. Inheritance by histones. Cell 1998;93:325-328.

8. Strahl BD, Allis CD. The language of covalent histone modifications. Nature 2000;403:41-45.

9. Hendzel MJ, Wei Y, Mancini MA, Van Hooser A, Ranalli T, Brinkley BR, Bazett-Jones DP, Allis CD. Mitosis-specific phosphorylation of histone $\mathrm{H} 3$ initiates primarily within centromeric heterochromatin during $\mathrm{G} 2$ and spreads in an ordered fashion coincident with mitotic chromosome condensation. Chromosoma 1997;106:348-360.

10. Wei Y, Yu L, Bowen J, Gorovsky MA, Allis CD. Phosphorylation of histone $\mathrm{H} 3$ is required for proper chromosome condensation and segregation. Cell 1999;97:99-109.

11. Thomson S, Mahadevan LC, Clayton AL. MAP kinase-mediated signalling to nucleosomes and immediate-early gene induction. Semin Cell Dev Biol 1999;10:205-214. 
12. Barratt MJ, Hazzalin CA, Cano E, Mahadevan LC. Mitogen-stimulated phosphorylation of histone $\mathrm{H} 3$ is targeted to a small hyperacetylationsensitive fraction. Proc Natl Acad Sci USA 1994;91:4781-4785.

13. Cheung $P$, Tanner KG, Cheung WL, Sassone-Corsi $P$, Denu JM, Allis CD. Synergistic coupling of histone $\mathrm{H} 3$ phosphorylation and acetylation in response to epidermal growth factor stimulation. Mol Cell 2000;5: 905-916.

14. Lo WS, Trievel RC, Rojas JR, Duggan L, Hsu J-Y, Allis CD, Marmorstein $\mathrm{R}$, Berger SL. Phosphorylation of serine 10 in histone $\mathrm{H} 3$ is functionally linked in vitro and in vivo to Gcn5-mediated acetylation at lysine 14. Mol Cell 2000:5:917-927.

15. Rundlett SE, Carmen AA, Suka N, Turner BM, Grunstein M. Transcriptional repression by UME6 involves deacetylation of lysine 5 of histone H4 by RPD3. Nature 1998;392:831-835

16. Sobel RE, Cook RG, Perry CA, Annunziato AT, Allis CD. Conservation of deposition-related acetylation sites in newly synthesized histones $\mathrm{H} 3$ and H4. Proc Natl Acad Sci USA 1995;92:1237-1241.

17. Roth SY, Allis CD. Histone acetylation and chromatin assembly-a single escort, multiple dances. Cell 1996;87:5-8.

18. Megee PC, Morgan BA, Mittman BA, Smith MM. Genetic analysis of histone $\mathrm{H} 4$ : essential role of lysines subject to reversible acetylation. Science 1990;247:841-845

19. Ma X-J, Wu J, Altheim BA, Schultz MC, Grunstein M. Deposition-related sites $\mathrm{K} 5 / \mathrm{K} 12$ in histone $\mathrm{H} 4$ are not required for nucleosome deposition in yeast. Proc Natl Acad Sci USA 1998;95:6693-6698.

20. Jackson V, Shires A, Tanphaichitr N, Chalkley R. Modifications to histones immediately after synthesis. J Mol Biol 1976;104:471-483.

21. Taddei A, Roche D, Sigarita J-B, Turner BM, Almouzni G. Duplication and maintenance of heterochromatin domains. J Cell Biol 1999;147: 1153-1166.

22. Utley RT, Ikeda K, Grant PA, Cote J, Steger DJ, Eberharter A, John S, Workman JL. Transcriptional activators direct histone acetyltransferase complexes to nucleosomes. Nature 1998;394:498-502.

23. $\mathrm{Ng} \mathrm{H}-\mathrm{H}$, Bird A. Histone deacetylases: silencers for hire. Trends Biochem Sci 2000;25:121-126.

24. Cosma MP, Tanaka T, Nasmyth K. Ordered recruitment of transcription and chromatin remodeling factors to a cell cycle- and developmentally regulated promoter. Cell 1999;97:299-311.

25. Fuks F, Burgers WA, Brehm A, Hughes-Davies L, Kouzarides T. DNA methyltransferase Dnmt1 associates with histone acetyltransferase activity. Nature Genetics 2000;24:88-91.

26. Brown KE, Guest SS, Smale ST, Hahm K, Merkenschlager M, Fisher AG. Association of transcriptionally silent genes with Ikaros complexes at centromeric hereochromatin. Cell 1997;91:845-854.

27. Koipally J, Renold A, Kim J, Georgopoulos K. Repression by Ikaros and Aiolos is mediated through histone deacetylase complexes. EMBO J 1999; 18:3090-3100

28. Sobel RE, Cook RG, Allis CD. Non-random acetylation of histone $\mathrm{H} 4$ by a cytoplasmic histone acetyltransferase as determined by a novel methodology. J Biol Chem 1994;269:18576-18582.

29. Kuo M-H, Brownell JE, Sobel RE, Ranalli TA, Cook RG, Edmondson DG, Roth SY, Allis CD. Transcription-linked acetylation by Gcn5p of histones $\mathrm{H} 3$ and $\mathrm{H} 4$ at specific lysines. Nature 1996;383:269-272.

30. Mizzen CA, Yang X-J, Kokubo T, Brownell JE, Bannister AJ, OwenHughes T, Workman J, Wang L, Berger SL, Kouzarides T, Nakatani Y, Allis CD. The $T_{A F} 250$ subunit of TFIID has histone acetyltransferase activity. Cell 1996;87:1261-1270.

31. Verruault A, Kaufman PD, Kobayashi R, Stillman B. Nucleosomal DNA regulates the core histone-binding subunit of the human Hat1 acetyltransferase. Curr Biol 1997;8:96-108.

32. Grant PA, Eberharter A, John S, Cook RG, Turner BM, Workman JL. Expanded lysine acetylation specificity of Gon5 in native complexes. J Biol Chem 1999;274:5895-5900.

33. Smith ER, Pannuti A, Gu W, Steurnagel A, Cook RG, Allis CD, Lucchesi JC. The Drosophila MSL complex acetylates histone $\mathrm{H} 4$ at lysine 16 , a chromatin modification linked to dosage comensation. Mol Cell Biol 2000;20:312-318.

34. Akhtar A, Becker PB. Activation of transcription through histone $\mathrm{H} 4$ acetylation by MOF, an acetyltransferase essential for dosage compensation. Mol Cell 2000;5:367-375
35. Turner BM, Birley AJ, Lavender J. Histone $\mathrm{H} 4$ isoforms acetylated at specific lysine residues define individual chromosomes and chromatin domains in Drosophila polytene nuclei. Cell 1992;69:375-384

36. Bone JR, Lavender JS, Richman R, Palmer MJ, Turner BM, Kuroda MI. Acetylated histone $\mathrm{H} 4$ on the male $X$ chromosome is associated with dosage compensation in Drosophila. Genes Dev 1994;8:96-104.

37. Zhang Y, LeRoy G, Seelig H-P, Lane WS, Reinberg D. The dermatomyositis-specific autoantigen $\mathrm{Mi2}$ is a component of a complex containing histone deacetylase and nucleosome remodeling activities. Cell 1998;95:279-289

38. Carmen AA, Griffin PR, Calaycay JR, Rundlett SE, Suka Y, Grunstein M. Yeast HOS3 forms a novel trichostatin A-insensitive homodimer with intrinsic histone deacetylase activity. Proc Natl Acad Sci USA 1999;96: $12356-12361$.

39. Imai S-I, Armstrong CM, Kaeberlein M, Guarente L. Transcriptional silencing and longevity protein Sir2 is an NAD-dependent histone deacetylase. Nature 2000;403:795-800.

40. Banéres J-L, Martin A, Parello, J. The $\mathrm{N}$ tails of histones $\mathrm{H} 3$ and $\mathrm{H} 4$ adopt a highly structured conformation in the nucleosome. J Mol Biol 1997;273: 503-508.

41. Hansen JC, Tse C, Wolffe AP. Structure and function of the core histone N-termini: More than meets the eye. Biochem 1998;37:17637-17641.

42. Grunstein M, Hecht A, Fisher-Adams G, Wan J, Mann RK, StrahlBolsinger S, Laroche T, Gasser S. The regulation of euchromatin and hetereochromatin by histones in yeast. J Cell Sci 1995;S19:29-36.

43. Lenfant F, Mann RK, Thomsen B, Ling XF, Grunstein M. All four core histone $\mathrm{N}$-termini contain sequences required for the repression of basa transcription in yeast. EMBO J 1996;15:3974-3985

44. Luger K, Mader AW, Richmond RK, Sargent DF, Richmond TJ. Crystal structure of the nucleosome core particle at $2.8 \AA$ resolution. Nature 1997;389:251-260.

45. Luger K, Richmond TJ. The histone tails of the nucleosome. Curr Opin Genet Dev 1998;8:140-146.

46. Kuo M-H, Zhou J, Jambeck $\mathrm{P}$, Churchill MEA, Allis CD. Histone acetyltransferase activity of yeast Gcn5p is required for the activation of target genes in vivo. Genes Dev 1998;12:627-639.

47. Chen H, Lin RJ, Xie W, Wilpitz D, Evans RM. Regulation of hormoneinduced histone hyperacetylation and gene activation via acetylation of an acetylase. Cell 1999;98:675-686.

48. Parekh BS, Maniatis T. Virus infection leads to localized hyperacetylation of histones $\mathrm{H} 3$ and $\mathrm{H} 4$ at the IFN- $\beta$ promoter. Mol Cell 1999;3:125-129.

49. Krebs JE, Kuo M-H, Allis CD, Peterson CL. Cell cycle-regulated histone acetylation required for expression of the yeast $\mathrm{HO}$ gene. Genes Dev 1999;13:1412-1421.

50. Hebbes TR, Clayton AL, Thorne AW, Crane-Robinson C. Core histone hyperacetylation co maps with generalised DNasel sensitivity in the chicken $\beta$-globin chromosomal domain. EMBO J 1994;13:1823-1830.

51. Ekwall K, Olsson T, Turner BM, Cranston G, Allshire RC. Transient inhibition of histone deacetylation alters the structural and functional imprint at fission yeast centromeres. Cell 1997:91:1021-1032.

52. Lavender JS, Birley AJ, Palmer MJ, Kuroda MI, Turner BM. Histone H4 acetylated at lysine 16 and other components of the Drosophila dosage compensation pathway colocalize on the male $X$ chromosome through mitosis. Chromosome Res 1994;2:398-404.

53. Gu W, Szauter P, Lucchesi JC. Targeting of MOF, a putative histone acetyltransferase, to the $\mathrm{X}$ chromosome of Drosophila melanogaster. Dev Genet 1998;22:56-64

54. Dhalluin C, Carlson JE, Zheng L, He C, Aggarwal AK, Zhou M-M. Structure and ligand of a histone acetyltransferase bromodomain. Nature 1999;399:491-496.

55. Jeppesen $\mathrm{P}$, Turner BM. The inactive $\mathrm{X}$ chromosome in female mammals is distinguished by lack of histone $\mathrm{H} 4$ acetylation, a marker for gene expression. Cell 1993;74:281-289.

56. O'Neill LP, Keohane AM, Lavender JS, McCabe V, Heard E, Avner P, Brockdorff N, Turner BM. A developmental switch in $\mathrm{H} 4$ acetylation upstream of Xist plays a role in $\mathrm{X}$ chromosome inactivation. EMBO $J$ 1999;18:2897-2907

57. Keohane AM, O'Neill LP, Belyaev ND, Lavender JS, Turner BM $\mathrm{X}$-inactivation and histone $\mathrm{H} 4$ acetylation in embryonic stem cells. Dev Biol 1996;180:618-630.

\section{BioEssays 22.9}


58. Gilbert SL, Sharp PA. Promoter-specific hypoacetylation of X-inactivated genes. Proc Natl Acad Sci USA 1999;96:13825-13830.

59. Lyko F, Paro R. Chromosomal elements conferring epigenetic inheritance. Bioessays 1999;21:824-832.

60. Zink D, Paro R. Drosophila Polycomb-group regulated chromatin inhibits the accessibility of a transactivator to its target DNA. EMBO J 1995;14: 5660-5671.

61. Cavalli G, Paro R. The Drosophila Fab-7 chromosomal element conveys epigenetic inheritance during mitosis and meiosis. Cell 1998;93:505-518

62. Cavalli G, Paro R. Epigenetic inheritance of active chromatin after removal of the main transactivator. Science 1999;286:955-958.

63. Archer SY, Meng S, Shei A, Hodin, RA. P21 $21^{\text {WAF1 }}$ is required for butyrate mediated growth inhibition of human colon cancer cells. Proc Natl Acad Sci USA 1998;95:6791-6796

64. Jones PA, Laird PW. Cancer epigenetics comes of age. Nat Genet 1999;21:163-167. 